\title{
Golf Learning: 3D Kinematics Approach to Long Drive Swing Shot
}

\author{
Agus Rusdiana $^{1, *}$, Hadi Sartono², Angga M Syahid ${ }^{2}$, Tian Kurniawan ${ }^{1}$ \\ ${ }^{1}$ Sports Science Study Program, Faculty of Sports and Health Education, Universitas Pendidikan Indonesia, Indonesia \\ ${ }^{2}$ Sport Coaching Education Study Program, Faculty of Sports and Health Education, Universitas Pendidikan Indonesia, Indonesia
}

Received August 17, 2021; Revised October 18, 2021; Accepted November 11, 2021

\begin{abstract}
Cite This Paper in the following Citation Styles
(a): [1] Agus Rusdiana, Hadi Sartono, Angga M Syahid, Tian Kurniawan, "Golf Learning: 3D Kinematics Approach to Long Drive Swing Shot," International Journal of Human Movement and Sports Sciences, Vol. 9, No. 6, pp. 1390 - 1395, 2021. DOI: 10.13189/saj.2021.090635.
\end{abstract}

(b): Agus Rusdiana, Hadi Sartono, Angga M Syahid, Tian Kurniawan (2021). Golf Learning: 3D Kinematics Approach to Long Drive Swing Shot. International Journal of Human Movement and Sports Sciences, 9(6), 1390 - 1395. DOI: 10.13189/saj.2021.090635.

Copyright $\odot 2021$ by authors, all rights reserved. Authors agree that this article remains permanently open access under the terms of the Creative Commons Attribution License 4.0 International License

\begin{abstract}
The aim of this study is to determine the difference between long drive swing mechanical movement and ball velocity among skilled and unskilled golfers using a 3D kinematics approach. The method used was descriptive quantitative, and the data analysis technique was an assessment of the average test difference. Moreover, the sample was 6 skilled and 6 amateur male player groups, with an average height of $1.67 \pm 2.43 \mathrm{~m}$, weight $72.4 \pm 86.3 \mathrm{~kg}$, and age $25.4 \pm 36.2$ years. According to the results, four indicators revealed significant differences among the ten kinematics variables investigated, including club speed at impact $(\mathrm{P}=0.038)$, lateral bend after impact ball $(\mathrm{P}=0.041)$, hip rotation at the top $(\mathrm{P}=0.045)$, and shoulder rotation $(\mathrm{P}=0.028)$. In summary, the long drive swing technique in producing maximum ball speed is dependent on the harmonization of the motion sequence from the lower body to the swing of the stick. Furthermore, the rotational speed of the hip joint at the beginning of the downswin followed by the shoulder angular velocity is a movement characteristic of professional players.
\end{abstract}

Keywords Golf, Long Drive Swing, Mechanics, Kinematic, Sports Biomechanics

\section{Introduction}

Biomechanics is the study of the structure and function of biological systems in terms of their mechanical systems [1]. Mechanics is a branch of physics that investigates motion and shape changes as a result of a force [2]. Meanwhile, sports biomechanics is a field of biomechanics that examines and analyzes movement to attain optimum efficiency, effectiveness, and injury reduction during training and competitions [3]. Implementing a comprehensive sports biomechanics analysis during an athlete's training or competition can have implications for performance improvement, rehabilitation, and injury prevention, increasing optimal sports performance [4].

Golf is an open-air sport played individually or in teams, whereby players compete to get the ball into the holes on the course with the fewest strokes possible. The most important thing in this game is the technique of hitting the ball, calmness and high concentration will affect someone's shot, which is the most crucial thing that golfers master [5]. In addition, there are three basic strategies for hitting the ball that must be done correctly to produce an accurate and precise shot. These three tactics are preparing the basic stance, holding the grip properly, and swinging the golf club. If these are properly mastered, they will result in strong and accurate strokes to achieve the best score and win the game [6]. Furthermore, the game of golf necessitates not only physical muscle strength but also intelligence, foresight, and accuracy [7].

In terms of motion mechanics, the technique of hitting golf is nearly identical to the swing technique in baseball. However, in baseball, the ball is hit at waist height, 
whereas in golf, the ball is hit on the ground [8]. Also, to get a long shot in baseball, the player not only expends the power of the arm swing, but also the speed of rotation of the upper body, which coincides with the swing of the golf club [9]. Coordination of the moment of impact, centrifugal force, and the correct swing movement can result in a more optimal stroke. Further, the main factors in a successful shot are combining the swing speed of the hands, arms, shoulder rotation, golf clubs, and stable foot support [10]. The phase of the long drive shot are as follows: full swing, backswing transition, downswing, and follow-through (figure 1). Strike errors usually occur during the backswing and downswing phases of long drive shots [11]. The backswing technique is a stick grip movement that is swung to a position above the head. Meanwhile, the downswing method is a stick grip movement that is swung until it reaches the ball impact position. These techniques must be mastered by players, in order to direct the ball to the intended target [12].

When the golfer hits the ball, their feet must be somewhat wider than their shoulders, and weight evenly distributed on both feet. Also, the player's knees must be bent slightly to provide extra thrust, when swinging the golf club [13]. Additionally, during the impact ball, 75\% of the weight is transferred to the forefoot and $25 \%$ to the back foot [14]. Based on the preceding background description, the purpose of this study was to determine the difference between long drive swing mechanical movement and ball velocity between skilled and amateur golf players using 3D kinematics variable analysis.

\section{Method}

This study uses comparative descriptive with quantitative approach. Comparative research is the study that compares the existence of one or more variables in two or more different samples [1]. Quantitative methods can be interpreted as research methods used to examine certain populations or samples. techniques are generally carried out randomly. Data collection uses research instruments. Data analysis is quantitative with the aim of testing predetermined hypotheses [2]. This study used the SPSS version 22.0 software (SPSS Inc., Chicago, IL), where the average and standard deviation were calculated as initial data for further calculations of normality, homogeneity, and hypothesis tests. To test the hypothesis, a one-way analysis of variance approach was used. This analysis allowed calculting the level of difference between skilled and amateur golf players with significant differences of 0.05 . The three-dimensional coordinate data of the signs affixed to each part of the player's joints were adjusted using the Butterworth low-pass filter method approach. This procedure was performed with a cut-off frequency of $15 \mathrm{~Hz}$ and used the residual analysis technique.

\subsection{Participants}

The samples consisted of 6 skilled and 6 amateur male player groups with average height $1.67 \pm 2.43 \mathrm{~m}$, weight $72.4 \pm 86.3 \mathrm{~kg}$, age $25.4 \pm 36.2$ years. Experienced group training consisted of skilled golf players over 10 years $(10.8 \pm 1.15$ years $)$. Futhermore, Experienced group training of amateur golf players have played golf less than 4 years $(3.9 \pm 0.94$ years $)$. All subjects provided their written consent on a letter that had before given to participants; in addition, the participants confirmed that they had not been injured. Prior to the data collection, subjects obtain detailed information about how procedures should be implemented.

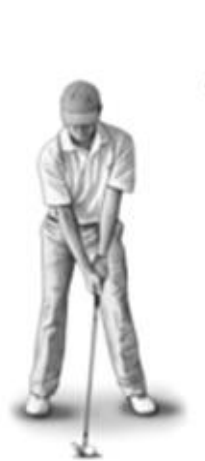

(a)

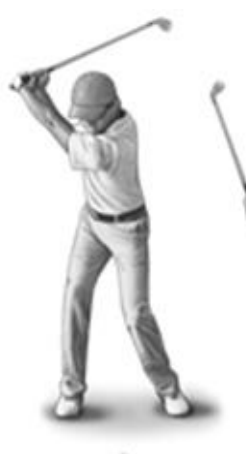

(b)

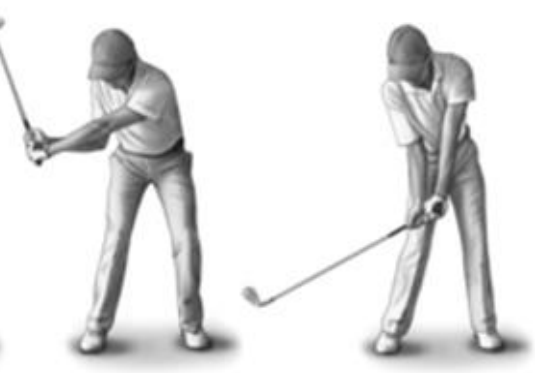

(c) (d)

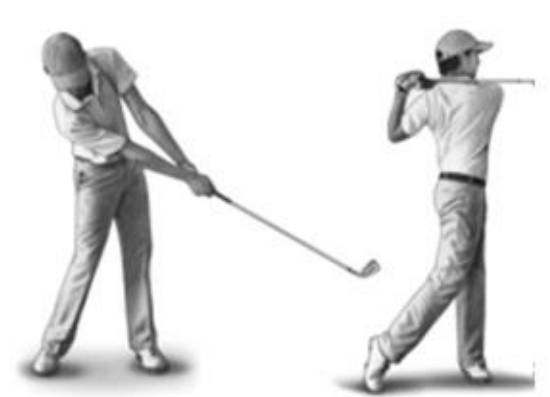

(e) (f)

Figure 1. Motion phase for long drive shot of swing full; (a-b) backswing, (b-c) transition, (c-e) downswing, (e-f) follow through 


\subsection{Instrument}

The study was conducted using 3 handy cams HC-D500 Full HD, a high-speed video camera (Phantom 145 USA), a calibration set, a dartfish promotion analysis software, and a speed radar gun (Bushnell Speed gun 101911, Italy).

\subsection{Kinematic Variable Analysis}

The kinematic indicators analyzed are trunk forward tilt (A), velocity of club stick (B), flexion of knee (C), the top of wrist hinge and leading arm angle (D), lateral bend (E), rotation of hip (F), and shoulder angular velocity $(\mathrm{G})$, as shown in Figure 2.
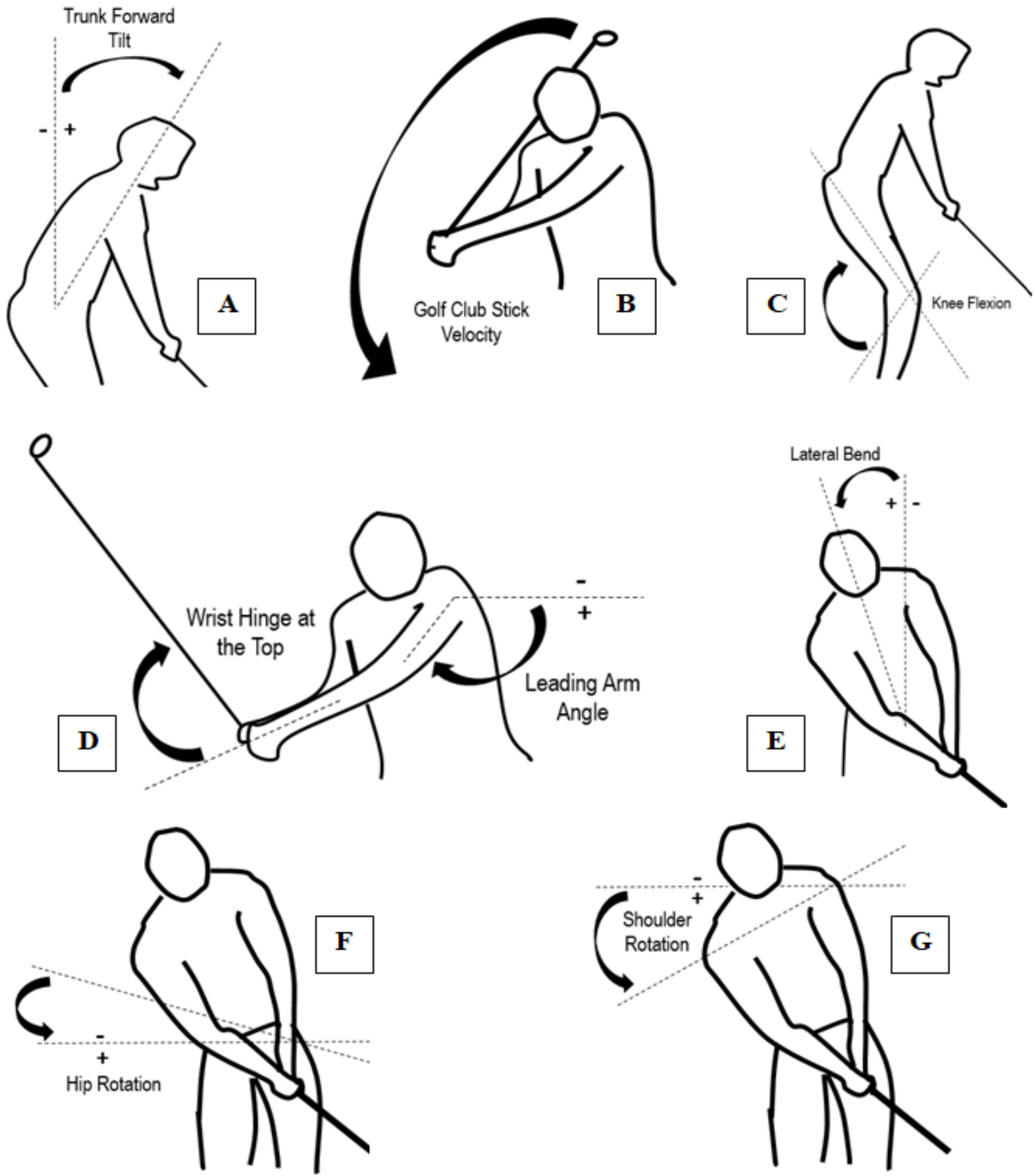

Figure 2. Kinematics variable analysis; A. forward tilt of trunk, B. velocity of club stick, C. flexion of knee, D. wrist hinge at the top and leading arm angle, E. lateral bend, F. hip rotation, and G. shoulder angular velocity 


\subsection{Procedure}

In the data collection process, players warmed up for about 10 minutes. They warm up by stretching the muscles of the legs, back, shoulders, and arms for a few minutes. After stretching the muscles, players were asked to do several swing movements using an iron stick 9. The purpose of this swing movement is to stretch the muscles, especially the arm, back and waist muscles. The session was then extended by hitting the long ball drive 10 times, with the best results being recorded for analysis. The ball velocity was measured by a radar speed gun used $250 \mathrm{~Hz}$ of shutter speed. Meanwhile, at a distance of $2 \mathrm{~m}$, video camera 1 was positioned perpendicular to behind the subject. Video cameras 2 and 3 were positioned perpendicular to the player at a distance of $3.5 \mathrm{~m}$ as well as $4 \mathrm{~m}$ above the subject standing position, respectively. The users configured the three cameras to meet the characteristics of the study. The settings used $250 \mathrm{~Hz}$ of frame rate, shuttle of speed of $500 \mathrm{~s}$, and 1/1200 s of exposure time. Furthermore, three dimensions data carried out using the direct linear transformation approach are developed by Aziz Karara [15].

\section{Results}

Table 1 shows the average and standard deviation of the ball speed during the long drive swing in golf. The skilled player group averaged $121 \pm 0.96 \mathrm{~m} . \mathrm{s}^{-1}$, while the amateur group averaged $79.5 \pm 1.23 \mathrm{~m} \cdot \mathrm{s}^{-1}$.

Table 2 shows the significance difference test of the kinematic chain of motion during long drive swing between skilled and amateur players. 10 kinematics variables data analyzed shows that 4 parameters with significant differences include speed $\mathrm{f}$ club speed at impact $(\mathrm{P}=0.038)$, lateral bend at impact moment $(\mathrm{P}=$ 0.041), hip rotation at the top $(\mathrm{P}=0.045)$, and shoulder rotation $(\mathrm{P}=0.028)$.

Table 1. Mean and SD of the ball velocity during the maximal long drive swing

\begin{tabular}{|c|c|c|c|c|}
\hline \multirow{3}{*}{ Subject } & \multicolumn{4}{|c|}{ Ball Velocity $\left(\mathbf{m} . \mathrm{s}^{-1}\right)$} \\
\hline & \multicolumn{2}{|c|}{ Skilled } & \multicolumn{2}{|c|}{ Amateur } \\
\hline & Mean & SD & Mean & SD \\
\hline 1 & 118 & 0.94 & 78 & 0.87 \\
\hline 2 & 112 & 0.72 & 83 & 0.91 \\
\hline 3 & 115 & 1.18 & 84 & 1.14 \\
\hline 4 & 124 & 0.95 & 72 & 0.85 \\
\hline 5 & 122 & 0.79 & 81 & 1.75 \\
\hline 6 & 136 & 1.14 & 79 & 1.86 \\
\hline Sum & 727 & 5.72 & 477 & 7.38 \\
\hline Mean & 121 & 0.96 & 79.5 & 1.23 \\
\hline
\end{tabular}

Table 2. Kinematics of analysis variables between skilled and amateur player groups

\begin{tabular}{|c|c|c|c|}
\hline \multirow{2}{*}{ Kinematics Variables } & \multicolumn{2}{|c|}{ Mean \pm SD } & \multirow{2}{*}{ P-Value } \\
\hline & Skilled & Amateur & \\
\hline Trunk Forward Tilt $\left({ }^{o}\right)$ & $33.0 \pm 0.42$ & $39.0 \pm 0.82$ & 0.867 \\
\hline Club Speed at Impact (s) & $0.54 \pm 0.91$ & $0.72 \pm 1.23$ & $0.038^{*}$ \\
\hline Backswing Movement Time (s) & $2.14 \pm 0.72$ & $2.21 \pm 1.27$ & 1.785 \\
\hline Maximal Knee Flexion $\left({ }^{\circ}\right)$ & $19.0 \pm 0.26$ & $24.0 \pm 0.49$ & 0.914 \\
\hline Wrist Hinge at the Top $\left({ }^{\circ}\right)$ & $27.0 \pm 0.49$ & $29.0 \pm 0.92$ & 1.248 \\
\hline Leading Arm Angle $\left({ }^{o}\right)$ & $210 \pm 0.63$ & $196 \pm 1.81$ & 0.686 \\
\hline Lateral Bend at Impact Ball $\left(^{\circ}\right)$ & $38.0 \pm 0.22$ & $12.0 \pm 0.64$ & $0.041^{*}$ \\
\hline Hip Rotation at the Top $\left({ }^{o}\right)$ & $36.0 \pm 0.61$ & $24.0 \pm 1.09$ & $0.045^{*}$ \\
\hline Shoulder Rotation $(\%)$ & $241 \pm 0.46$ & $198 \pm 1.13$ & $0.028 *$ \\
\hline
\end{tabular}

*significant difference at level $\leq 0.05$ 


\section{Discussion}

The aim of this study is to determine the difference between long drive swing mechanical movement and ball velocity between skilled and amateur golf players using kinematics variable analysis. According to the research, the skilled player group average ball speed was higher than the amateur player group. The findings are similar to those of a badminton smash between Indonesian national athletes and university-level players, in which the shuttlecock velocity was higher in the national team player group [16]. Following that, this study reported that based on handball throwing, the ball speed was higher in the senior than junior team group. Furthermore, the factor that affects the ball speed occurs during the backswing phase, when the club stick speed reaches the impact ball, which averages $0.51 \mathrm{sec}$ for skilled players [17]. Professional golfers have a speed time of $0.72 \mathrm{sec}$ from the starting position to the maximum backswing [18]. Meanwhile, at the greatest position, the backswing moves to the downswing phase, lasting an average of $0.23 \mathrm{sec}$ [19]. Moreover, four indicators show significant differences among the ten kinematics variables studied, namely club speed at impact, lateral bend after impact ball, hip rotation at the top, and shoulder rotation. Also, the rotational speed of the hip and torso contributes $10 \%$ of the total linear velocity during the downswing phase, for professional players [20].

The measurements of the shoulder joint rotation at the top of the backswing has been previously discussed in several studies [21-24]. Overall, this angular, obtained with regard to the frontal plane,was on average 90 . The results of our study obtained with the skilled golfers $(241 \% \pm 0.46)$ are in agreement with this mean value. However, the amateur group golfers produced significantly greater shoulder rotation angles $(198 \% \mathrm{~s} \pm$ 1.13). Only the results of Burden [25] reported that male professional golfers normally rotated their shoulders between $390 \%$ and $425 \%$ when using a driver club. This greater amplitude can be explained by an evaluation of overswing in the female experienced golfers tested. Nevertheless, the results of Jobe [26] suggested that men and women demonstrated similar firing patterns in the shoulder muscles during the golf swing. But this finding does not preclude the possibility that there may be differences in muscle firing patterns and biomechanics in other parts of the body [27].

At the maximum height of the backswing phase, the right arm elbow is bent, abducted at the elbow joint to approximately $75^{\circ}$ to $90^{\circ}$. There was a significant difference in the average time duration achieved during the downswing phase between professional and university-level players being $0.23 \mathrm{sec}$ and $0.54 \mathrm{sec}$, respectively [28]. Additionally, in the unskilled golfer group, there is a notable distinction in the backswing phase when the left arm swings back with the elbow joint bent about $22^{\circ}$. According to a study by Gryc [29], the left arm should be perpendicular to the direction of the club stick. This is consistent with the findings in the skilled golfer group, where the perpendicular arm averaged $4^{\circ}$. In the follow-through phase, the torso position shifts laterally, influencing the direction of the target directionand contributing to the speed of the ball [30]. Furthermore, the results of this study revealed that the lateral position of the bend after impact has a significant effect on ball speed, with an average of $38^{\circ}$ and $12^{\circ}$ of the skilled and the amateur player groups, respectively.

\section{Conclusions}

The average speed of the ball produced by the skilled group $\left(121 \mathrm{~m} \cdot \mathrm{s}^{-1}\right)$ is higher than that of the amateur group $\left(79.5 \mathrm{~m} . \mathrm{s}^{-1}\right)$. The skilled player group seem to produce a swing with larger hip and shoulder joint rotation angles at the top of the backswing. Futhermore, these four kinematic results showed a significant differences in the club speed at impact, lateral bend after impact ball, hip rotation at the top, and shoulder rotation. The rotation of the hip joint at the beginning of the downswing, followed by the angular velocity of the shoulder joint is a movement characteristic of the skilled player group. Also, during the follow-through phase after the ball impact, the lateral torso position is the main factor in determining the target and ball speed. The joint movement angular velocity from the lower body to the stick swing phase is critical to the success of the long drive swing technique in producing maximum ball speed.

\section{REFERENCES}

[1] Knudson D. Qualitative biomechanical principles for application in coaching. Sport Biomech. 2007;6(1):109-18.

[2] Keogh JWL, Hume PA. Evidence for biomechanics and motor learning research improving golf performance. Sport Biomech. 2012;11(2):288-309.

[3] Horan SA, Kavanagh JJ. The control of upper body segment speed and velocity during the golf swing. Sport Biomech. 2012;11(2):165-74.

[4] Guadagnoli M, Holcomb W, Davis M. The efficacy of video feedback for learning the golf swing. J Sports Sci. 2002;20(8):615-22.

[5] Chu Y, Sell TC, Lephart SM. The relationship between biomechanical variables and driving performance during the golf swing. J Sports Sci. 2010;28(11):1251-9.

[6] Wang JJ, Yang PF, Ho WH, Shiang TY. Determine an effective golf swing by swing speed and impact precision tests. J Sport Heal Sci [Internet]. 2015;4(3):244-9. Available from:http://dx.doi.org/10.1016/j.jshs.2014.12.00 3. 
[7] Johnson D, McPhee J. Predictive dynamic simulation of the golf swing, including golfer biomechanics and distributed flexibility in the shaft. Procedia Eng [Internet]. 2014; 72:799-804. Available from: http://dx.doi.org/10.1016/j.pr oeng.2014.06.138.

[8] Stastny P, Maszczyk A, Tomankova K, Kubovy P, Richtrova M, Otahal J, et al. Kinetic and Kinematic Differences in a Golf Swing in One and Both Lower Limb Amputees. J Hum Kinet. 2015;48(1):33-41.

[9] Sung DJ, Park SJ, Kim S, Kwon MS, Lim YT. Effects of core and non-dominant arm strength training on drive distance in elite golfers. J Sport Heal Sci [Internet]. 2016; 5(2):219-25. Available from: http://dx.doi.org/10.1016/j.js hs.2014.12.006

[10] Smith A, Roberts J, Wallace E, Kong PW, Forrester S. Golf coaches' perceptions of key technical swing parameters compared to biomechanical literature. Int J Sport Sci Coach. 2015;10(4):739-56.

[11] Ferdinands RED, Kersting UG, Marshall RN. A twenty-segment kinematics and kinetics model for analysing golf swing mechanics. Sport Technol. 2013;6(4):184-201.

[12] Ibarguen EA. Weight Transfer, Golf Swing Theory and Coaching: A Commentary. Int J Sports Sci Coach. 2008;3(1_suppl):65-7.

[13] Meister DW, Ladd AL, Butler EE, Zhao B, Rogers AP, Ray CJ, et al. Rotational biomechanics of the elite golf swing: Benchmarks for amateurs. J Appl Biomech. 2011;27(3):242-51.

[14] Myers J, Lephart S, Tsai YS, Sell T, Smoliga J, Jolly J. The role of upper torso and pelvis rotation in driving performance during the golf swing. J Sports Sci. 2008;26(2):181-8.

[15] Meister DW, Butler EE, Rose J, Rogers AP, Ray CJ, Zhao B, et al. Rotational Biomechanics of the Elite Golf Swing: Benchmarks for Amateurs. J Appl Biomech. 2016;27(3):242-51.

[16] Gryc T, Zahalka F, Maly T, Mala L, Hrasky P. Movement's analysis and weight transfer during the golf swing. J Phys Educ Sport. 2015;15(4):781-7.

[17] Nesbit SM, McGinnis R. Kinematic analyses of the golf swing hub path and its role in golfer/club kinetic transfers. J Sport Sci Med. 2009;8(2):235-46.

[18] Evans K, Tuttle N. Improving performance in golf: Current research and implications from a clinical perspective. Brazilian J Phys Ther. 2015;19(5):381-9.

[19] Langdown BL, Bridge M, Li FX. Movement variability in the golf swing. Sport Biomech. 2012;11(2):273-87.

[20] Sim M, Kim JU. Differences between experts and novices in kinematics and accuracy of golf putting. Hum Mov Sci. 2010;29(6):932-46.

[21] Richards J, Farrell M, Kent J, Kraft R. Weight transfer patterns during the golf swing. Res Q Exerc Sport. 1985;56(4):361-5.

[22] Hughes MD, Bartlett RM. The use of performance indicators in performance analysis. $\mathrm{J}$ Sports Sci. 2002;20(10):739-54.

[23] Christie CA. and Club Head Speed in Mature Golfers '. 1998;811-5.

[24] Jenkins S. Golf Coaching and Swing Plane Theories. Int J Sports Sci Coach. 2007;2(1_suppl):1-24.

[25] Burden AM, Grimshaw PN, Wallace ES. Hip and shoulder rotations during the golf swing of sub-10 handicap players. J Sports Sci. 1998;16(2):165-76.

[26] Tinmark F, Hellström J, Halvorsen K, Thorstensson A. Elite golfers' kinematic sequence in full-swing and partialswing shots. Sport Biomech. 2010;9(4):236-44.

[27] Bourgain M, Hybois S, Thoreux P, Rouillon O, Rouch P, Sauret C. Effect of shoulder model complexity in upper-body kinematics analysis of the golf swing. J Biomech. 2018;75:154-8.

[28] Kong PW, Forrester S, Wallace E, Roberts J, Smith A. Golf Coaches' Perceptions of Key Technical Swing Parameters Compared to Biomechanical Literature. Int J Sports Sci Coach. 2015;10(4):739-55.

[29] Sharp RS. On the mechanics of the golf swing. Proc R Soc A Math Phys Eng Sci. 2009;465(2102):551-70.

[30] Kim J-I, Ha J-H. Comparison of Two and Three Dimensional Methods for Analysis of Kinematic Variables in the Golf Swing. J Golf Stud. 2020;14(2):221-30. 